\title{
Correction to: Announcement: Howard Rosenbrock Prize 2020
}

\section{Nikolaos V. Sahinidis ${ }^{1}$}

Published online: 8 June 2021

(c) Springer Science+Business Media, LLC, part of Springer Nature 2021

\section{Correction to: Optimization and Engineering https://doi.org/10.1007/s11081-021-09649-5}

In the original publication of the article the name of the first prize winner was published incorrectly. The first winner of the prize is Fränk Plein who was a PhD student at the time when the winning article was written. The correct citation of the winning article is:

Labbé M, Plein F, Schmidt M (2020) Bookings in the European gas market: Characterization of feasibility and computational complexity results. Optimization and Engineering 21:305-334

Publisher's Note Springer Nature remains neutral with regard to jurisdictional claims in published maps and institutional affiliations.

The original article can be found online at https://doi.org/10.1007/s11081-021-09649-5.

Nikolaos V. Sahinidis

nikos@gatech.edu

1 H. Milton Stewart School of Industrial \& Systems Engineering and School of Chemical \& Biomolecular Engineering, Georgia Institute of Technology, Atlanta, GA, USA 